\title{
Reticulocyte Mean Corpuscular Volume
}

National Cancer Institute

\section{Source}

National Cancer Institute. Reticulocyte Mean Corpuscular Volume. NCI Thesaurus. Code C114215.

The determination of the average reticulocyte volume in a blood sample. 